\title{
Designing English Syllabus for Islamic Education Study Program at IAIN Palopo
}

\author{
Reski Jayanti Sagita1 ${ }^{1}$, Sahraini², Andi Tenrisanna Syam ${ }^{3}$ \\ State Islamic Institute (IAIN Palopo), Indonesia \\ sahraini@iainpalopo.ac.id
}

\begin{abstract}
This research aimed to design the English syllabus for first semester students of the Islamic Education Study Program at IAIN Palopo. Based on the observation in June 2019, the researcher found several problems from the previous syllabus, such as the syllabus used general English, not specific English; the syllabus served a little portion of the discussion on topics of students' needs and interests of Islamic Education. The research design used in this research was Research and Development $(R \& D)$ utilized the $4 D$ model. It consists of defining, designing, developing, and disseminating. The procedures included analyzing English materials needed by the students of the Islamic Education study program then design the syllabus. The designed English syllabus for students of the Islamic Education study program at IAIN Palopo includes learning goals, learning material, learning methodology, learning indicators, and learning media. The product was tried out to the second semester of students of the Islamic Education study program at IAIN Palopo. The instruments were used in this research were questionnaires for need analysis and observation sheets for three expert validators and students' perception. In this research, three experts were involved in order to validate the product. There were five systematic aspects that they validate of the product: Format Syllabus, Syllabus Content, Language and Writing, and Time allocation. Therefore, the result indicated that based on the experts'validation as well as try-out design result, the product of this research was appropriate to be applied for students of the Islamic study program in the first semester as the primary syllabus for the English course.
\end{abstract}

Keywords: Design, Syllabus, English for Islamic Education.

\section{INTRODUCTION}

English as a foreign language (EFL) teaching is considered to be a compulsory subject at IAIN Palopo where the students have to pass four until six credits of English courses before graduation especially for non-English Department. EFL consists of two categories, including English for General Purposes (EGP) and English for Specific Purposes (ESP). EGPdefined as an English teaching that teaches overall English competence to the students where needs cannot be readily specified. Whereas ESP refers to an English teaching in which all the content and the method are given based on the students' needs. Based on the observation by the researcher, Islamic Education Study Program is one of the non-English departments at IAIN (Institut Agama Islam Negeri) Palopo which learn English for three semester or six credits. This study program changed over from applying EGP to ESP for English course named English for Islamic Education. It is especially intend to meet particular instructional objectives such as to enable students reading English text, writing an English paper, listening an English speech, making presentation end etc. that is relevant with the students' field of study i.e Islamic Education. However, the 
existing syllabus mostly deals with the general English that gives a little portion of the discussion on topics of students' need and interest about Islamic Education. It can be inferred that Islamic Education study program at IAIN Palopo did not have a suitable syllabus for this course yet. An appropriate syllabus is an important item in teaching and learning considering syllabus consists of learning activities and objectives. According to Cooper and Cuseo (1989) "a good syllabus has been cited in a survey of 200 , administrators, and students as the element most often contributing to successful college teaching". In that way, syllabus can be defined as a list of plan that is arranged before initiating a course. Related to the delimitation of the problem, the researcher formulated the research question as follows: What is the appropriate syllabus for Islamic Education Study Program students of IAIN Palopo? Based on the formulation of the problem, the researcher determined the objective of the research was to design an appropriate English syllabus for Islamic Education Study Program students of IAIN Palopo.

\section{METHODS}

\section{Research Design}

This research is categorized as Research and Development (R \& D) method. R \& D is a research method which can be used to produce a particular product and test the effectiveness of the product. In producing the product, the researcher firstly identified the needs (using survey which is qualitative in nature), develops a product, and then tests the effectiveness of the product (using an experiment). The product can be in the form of a syllabus, a model, a pattern, a procedure, a book, a module, a package, or a program. It is also be able to be used to develop the existing product. In this research method, the researcher would identify the learners' needs, design a product, try-outs the effectiveness of the instructional materials, and disseminates the product. In this study, the researcher will design a syllabus by utilizing 4-D model which is developed by S. Thiagarajan, Dorothy S. Semmel, and Melvyn I. Semmel.

\section{Research Procedure}

In this study, 4-D model has four main phases such as:

\section{Defining}

In this phase,the researcher collected the information about the learners' needs for learning English. The information was about target needs (needs, lacks, and wants) and learning needs (activities and setting). The researcher also did interview with the English lecturer, Islamic lecturers' and the alumnus of Islamic Education Study Program for additional information about the learners' needs. This analysis was used by the researcher to determine the suitable English syllabus for the Islamic Education Study Program Students of IAIN Palopo.

\section{Designing}

In this phase,the researcher designedthe product based on the result of learners' need analyses. The researcher designed a product which refers to an English syllabus based on defining phase previously.

\section{Developing}

In this phase, the researcher developed the English syllabus based on the experts 'and users' validity as well as the result of try-out. In this step, the researcher developed the product with good validities from three experts' judgments (Curriculum developer, Islamic Education lecturer/Islamic material expert, English lecturer/English material expert) and the users (learners). It purposed to get some feedback which revises the syllabus based on them. In this phase, the materials that had been designed and developed will be revised again as a final draft of the product. 


\section{Disseminating}

The product that had been developed and revised based on the judgments previously would be disseminated in this phase. It would be published trough seminar, social media, journal, etc. for supporting disseminating.

\section{Location and Time of the Research}

This research was conducted at State Islamic Institute of Palopo, South Sulawesi especially for students of Islamic Education Study Program. It was conducted on June 2019- June 2020.

\section{Subject and Object of the Research}

The Population in this research was all the students at the first semester, Islamic Education Study Program, Tarbiyah and Teacher Training Faculty, they are five classes in the class of 2018 with amount of students is 181 . The sample of this research was 70 students that had been conducted by using random sampling technique.

\section{Technique and Data Collection Instrument}

1. Interview, the researcher did some interviews with Islamic students and Islamic Education teachers. The interviews are used to collect the information about target need (goal in learning English).

2. Questionnaires, the questionnaires items consists of some target needs (necessity, wants, lacks)and target needs that was spreaded through google form.

\section{Data Analysis Techniques}

1. Interview, the result of interview had been analyzed by using descriptive qualitative method.

2. Questionnaire, the conducted data from the needs analysis questionnaire, which are distributed to the learners in need assessment phase, is described based on the answers that the learners choose to represent their needs. The result of this need assessment questionnaire will be calculated using the following formula.

$$
\begin{aligned}
& \qquad X=\frac{\sum x}{N} \times 100 \% \\
& X=\text { the mean } \\
& \sum x=\text { the number of the students who have the same answer } \\
& N=\text { the total number of the students }
\end{aligned}
$$

After calculating the mean score of each material topic, the researcher would define them as an appropriate English syllabus for Islamic Education

Table 3.1: Classification Students' Perception about the Syllabus Materials

\begin{tabular}{cccc}
\hline Score & Percentage & Qualification & Classification \\
\hline $3,6-4$ & $90 \%-100 \%$ & Excellent & Can be used without revision \\
$2,6-3,5$ & $65 \%-89 \%$ & Good & Can be used with a little bit revision \\
$1,6-2,5$ & $40 \%-64 \%$ & Fairly & Can be used with much revision \\
\hline
\end{tabular}


$0-1,5$

$0 \%-39 \%$

Poor

Cannot be used yet

\section{RESULTS}

1. The Result of Interview

There were two items of the questions used as interview guide: (1) in your opinion, how important is English for Islamic Education? and (2) Explain your reason of the answer of the first question. There were several statements about these questions as representative answered of Islamic students:

"I think English is very important to learn because it is an international language because if we want to continue our study abroad, we will need English for study and communication"

"English is very important to us because it will help us to delivered Islamic speech around the world. Without knowing English, it is impossible to do it considering English is a worldwide language"

2. The Result of Need Analysis Questionnaire

a. Target Need

1) Need

The first question of needs was about the Islamic students' goal in learning English. The results were $25 \%$ of students chose to use English for teaching Islamic Education, $48 \%$ of students chose to use English for helping them to understand Islamic Education material references (oral and written) that served in English, 13\% of students chose to use English for delivering Islamic speech, and 29\% of students chose to use English for assisting them in further education.

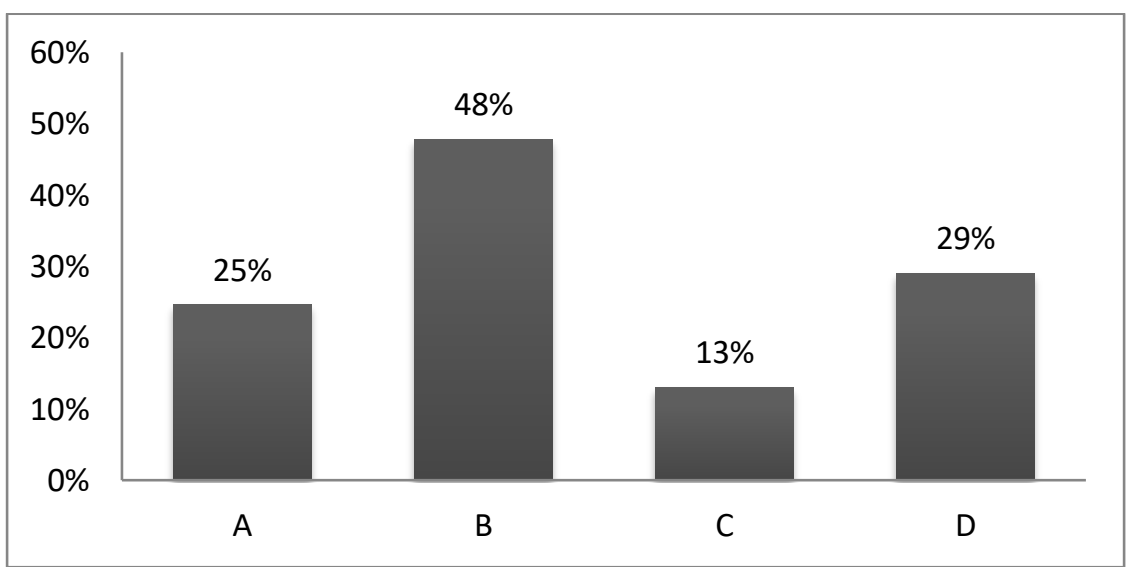

Figure 4.1: the Islamic students' goal in learning English

b. Lacks

For the question number 3, it was about Islamic students TOEFL scores. Based on the answer, $93 \%$ of students had not ever taken a test at all. The rest, $1 \%$ of students 
obtained $>500$ of TOEFL scores; $1 \%$ of students again obtained 451-499 of TOEFL scores; and $4 \%$ students obtained $<424$ of TOEFL scores.

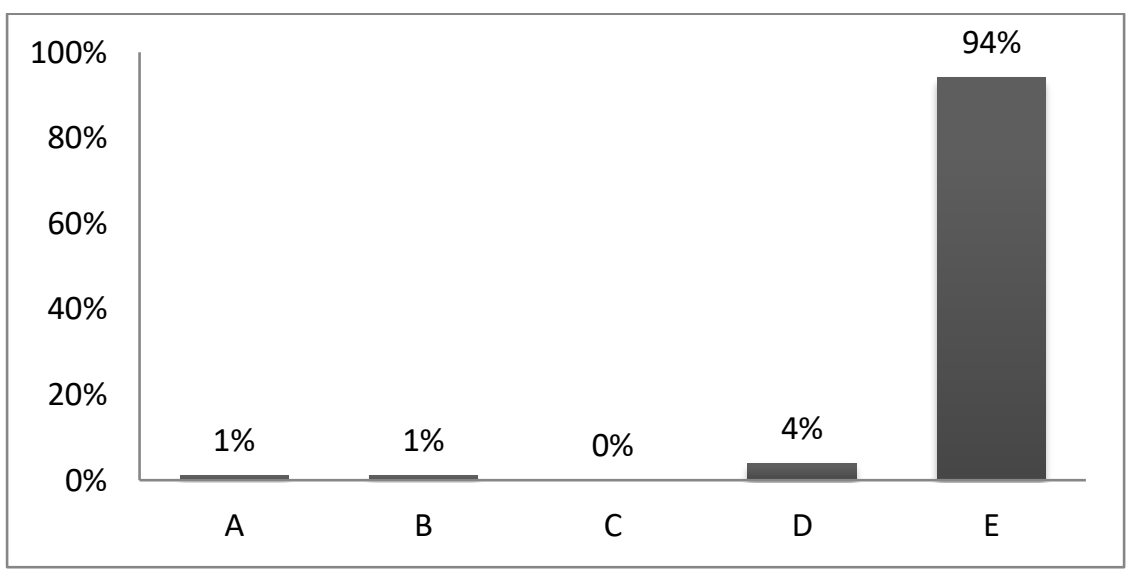

Figure 4.2: Islamic students TOEFL score

c. Wants

The following question is about Aqidah/Islamic belief topic that is interesting for the students to study in the English for Islamic Education course. There were $80 \%$ of students chose Ilahiah, namely discussion of something related to ilah (God) such as the form of Allah, the names of Allah, and the attributes of Allah, and others; 38\% of students chose Nubuwah, which is a discussion of everything related to prophets and messengers including talk about the books of Allah, miracles and so on; $20 \%$ of students chose Ruhaniah, namely the discussion of everything related to the metaphysical realm, such as angels, jinn, devils, demons and spirits; and $25 \%$ of students chose Sam'iyah, which is a discussion of everything that can only be known through sam'i namely the proof of naqli in the formof the Koran and as-Sunnah, such as the realms of barzakh, afterlife, grave doom, and so on.

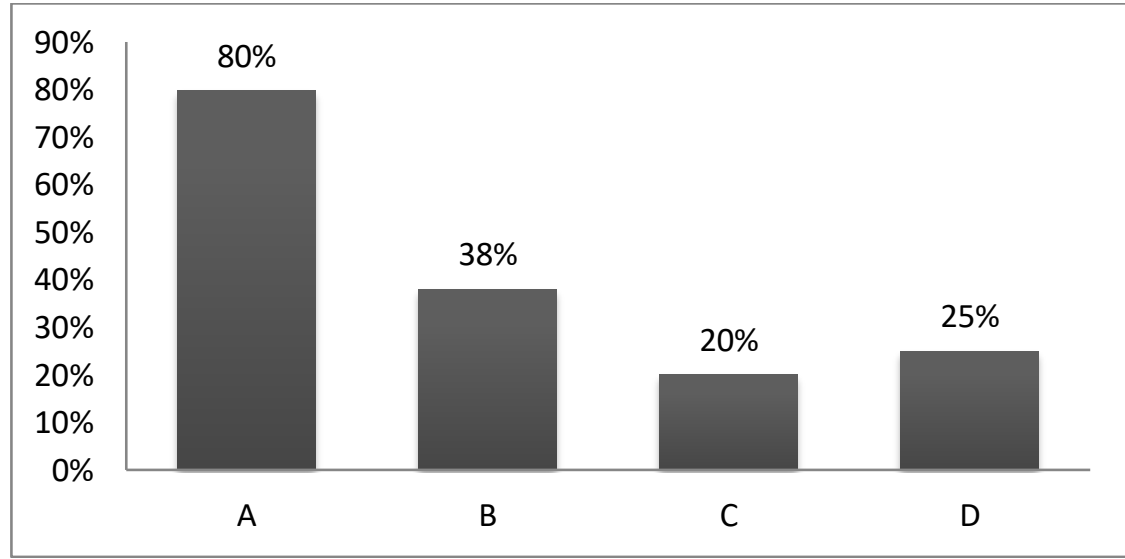

Figure 4.3 :Students preferred Islamic topic 
b. Learning Needs

1) Activities

The next question was about the right sequence for learning English in students' opinion. There were $48 \%$ of stduents chose the sequence of listening, speaking, reading, writing; $36 \%$ of students chose the sequence of listening, reading, speaking, writing; $9 \%$ of students chose the sequence of speaking, listening, reading, writing; and $10 \%$ of students chose the sequence of speaking, reading, writing, listening.

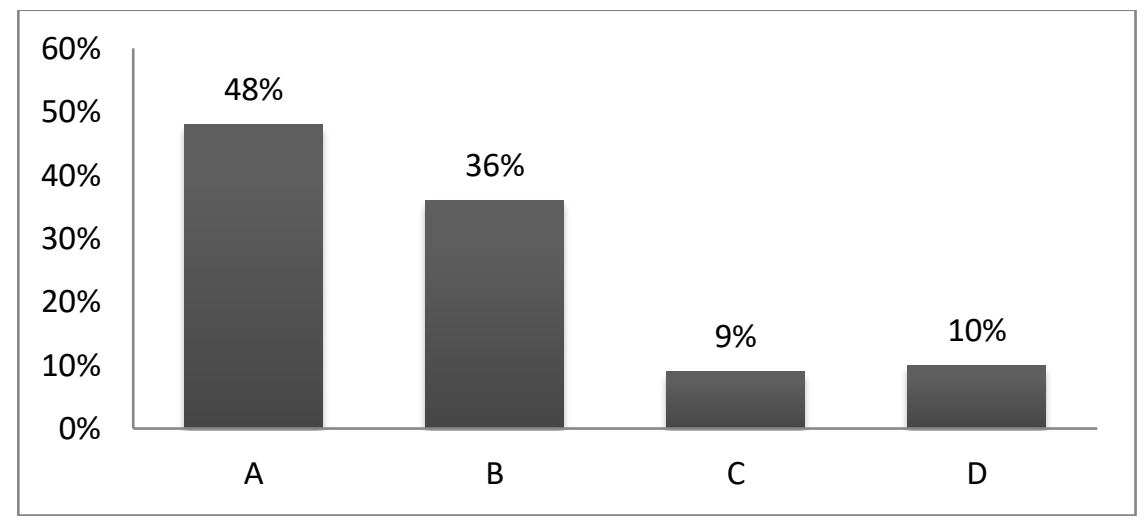

Figure 4.3 :Sequence English activities

2) Setting

The next question was about preferred English task activities by the Islamic students.There were $29 \%$ of students chose individual task, $29 \%$ chose pairing task, and $62 \%$ chose grouping of 3-5 task.

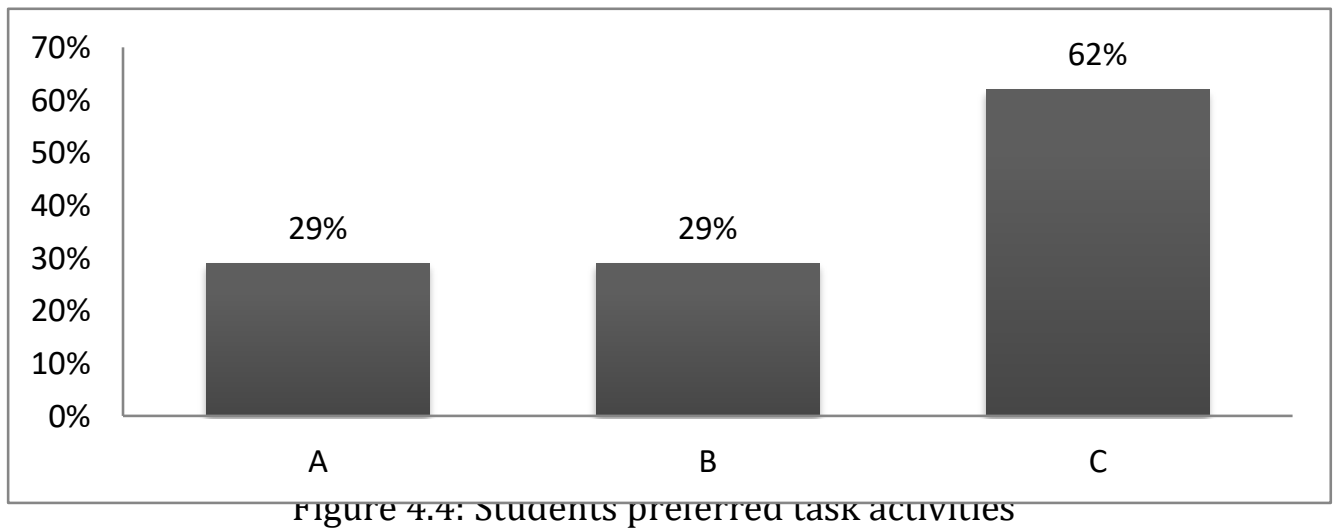

3) Additional information

The last question again was not a multiple choice questions. It was about the required things by Islamic students in order to improve their English skills. Most of the students answered that they need more vocabulary and how to pronounce it.

c. The Result of Designed Syllabus

Based on the result of need analysis above and refers to Indonesian National Qualification Framework, the result of the designed syllabus as follows: 


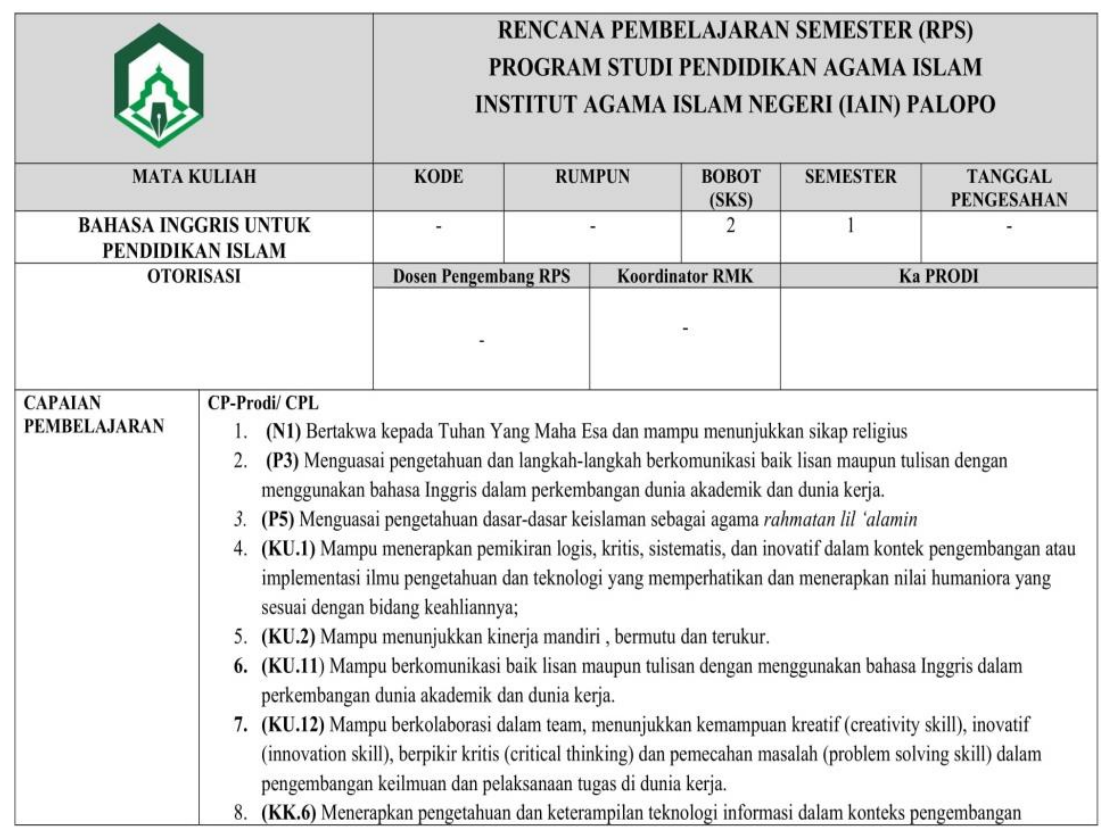

\begin{tabular}{|l|l|}
\hline \multicolumn{1}{|c|}{ keilmuan dan implementasi bidang keahlian secara efektif dan berdaya guna. } \\
\cline { 2 - 3 } & $\begin{array}{l}\text { Capaian Pembelajaran Mata Kuliah (CPMK) } \\
\text { 1. Mahasiswa mampu mengemukakan Rukun Islam dan Rukun Iman menggunakan Bahasa Inggris. } \\
\text { 2. Mahasiswa mampu memahami dan menjelaskan tata cara (how to do something) thaharah dan shalat } \\
\text { menggunakan Bahasa Inggris. } \\
\text { 3. Mahasiswa mampu mengemukakan aktivitas positif sebagai seorang muslim di kehidupan sehari-hari } \\
\text { menggunakan Bahasa Inggris. } \\
\text { 4. Mahasiswa mampu mendeskripsikan (describing) tokoh-tokoh Islam inspiratif menggunakan Bahasa Inggris. } \\
\text { 5. Mahasiswa mampu membuat biografi singkat tokoh-tokoh Islam inspiratif menggunakan Bahasa Inggris. } \\
\text { 6. Mahasiswa mampu mengemukakan hal-hal yang berkaitan dengan upaya membangun generasi Islami. } \\
\text { menggunakan Bahasa Inggris. } \\
\text { 7. Mampu membuat rencana (planning) menggunakan Bahasa Inggris. } \\
\text { 8. Mahasiswa mampu mengemukakan hal-hal yang berkaitan dengan pengamalan Rukun Iman menggunakan } \\
\text { Bahasa Inggris. } \\
\text { 9. Mahasiswa mampu mengemukakan hal-hal yang berkaitan dengan kisah teladan rasul ulul azmi menggunakan } \\
\text { Bahasa Inggris. } \\
\text { 10. Mahasiswa mampu memberi nasihat tentang amar ma'ruf nahi mungkar menggunakan bahasa Inggris } \\
\text { 11. Mahasiswa mampu mengemukakan hal-hal yang halal dan haram (dilakukan dan dikonsumsi) bagi umat islam } \\
\text { menggunakan Bahasa Inggris. } \\
\text { 12. Mahasiswa mampu mengemukakan pendapat tentang Pendidikan Islam di Indonesia menggunakan Bahasa } \\
\text { Inggris. }\end{array}$ \\
\hline $\begin{array}{l}\text { Mata kuliah Bahasa Inggris untuk PAI ini merupakan mata kuliah bidang studi pada program S-1 Program Pendidikan } \\
\text { Agama Islam dengan status mata kuliah wajib. Mata kuliah ini diberikan kepada mahasiswa semester I dengan bobot } \\
\text { mata kuliah 2 SKS. Mata kuliah ini membahas mengenai penggunaan Bahasa Inggris (basic) dalam pembelajaran } \\
\text { Pendidikan Islam. Ketrampilan yang diajarkan meliputi keterampilan mengucapkan kata dalam bahasa Inggris, } \\
\text { mendengar, berbicara, membaca, dan menulis. Sedangkan komponen bahasa pendukung ketrampilan berbahasa yang } \\
\text { diajarkan adalah kosa kata dan tata bahasa. Seluruh ketrampilan dan komponen berbahasa tersebut disajikan dalam } \\
\text { setiap pertemuan secara terintegrasi agar mahasiswa benar- benar memiliki kemampuan yang mumpuni setelah lulus. }\end{array}$ \\
\hline Deskripsi Singkat
\end{tabular}




\begin{tabular}{|c|c|}
\hline Bahan Kajian & $\begin{array}{l}\text { 1. Kosa kata yang berkaitan dengan Rukun Islam, Rukun Iman, tharah, sholat, aktivitas postif sebagai seorang } \\
\text { muslim, tokh-tokoh islam inspiratif, upaya membangun generasi Islami, kisah teladan rasul Ulul Azmi, Amar } \\
\text { Ma'ruf Nahi Mungkar, hal-hal yang haram dan halal, dan pendidikan Islam di Indonesia. } \\
\text { 2. The five pillars of Islam } \\
\text { 3. The six pillars of faith } \\
\text { 4. to do (do,did, does) } \\
\text { 5. to be (am, is, are) + verb-ing } \\
\text { 6. to be (am, is, are) + ANA (Adjective, Noun, Adverb) } \\
\text { 7. to have. } \\
\text { 8. will + verb I } \\
\text { 9. active and passive voice } \\
\text { 10. Question word ( } 5 \text { W + IH) } \\
\text { 11. asking and giving advice } \\
\text { 12. showing prohibition } \\
\text { 13. asking and giving opinion }\end{array}$ \\
\hline Pustaka & $\begin{array}{l}\text { Utama : } \\
\text { 1. DarwisDjamaluddin. 2010. English for Islamic Studies. Bandung: PT. RajagrafindoPersada. } \\
\text { 2. Arsyad,Azhar.2013. Dasar-dasar Penguasaan Bahasa Inggris. Yogyakarta: PUSTAKA BELAJAR } \\
\text { 3. Fadzlillah, N. A., Man, Y. B. C., Jamaludin, M. A., Rahman, S. A., \& Al-Kahtani, H. A. (2011). Halal food } \\
\text { issues from Islamic and modern science perspectives. In 2nd International Conference on Humanities, } \\
\text { Historical and Social Sciences (Vol. 171, pp. 59-163). } \\
\text { 4. Zaenab, S. (2019). FAMILY'S MESSENGERS STORIES OF ULUL AZMI IN THE QURAN (A } \\
\text { THEMATIC INTERPRETATION). } \\
\text { Website: } \\
\text { 1. Wikihow.com }\end{array}$ \\
\hline & $\begin{array}{c}\text { Pendukung: } \\
\text { Book: }\end{array}$ \\
\hline
\end{tabular}

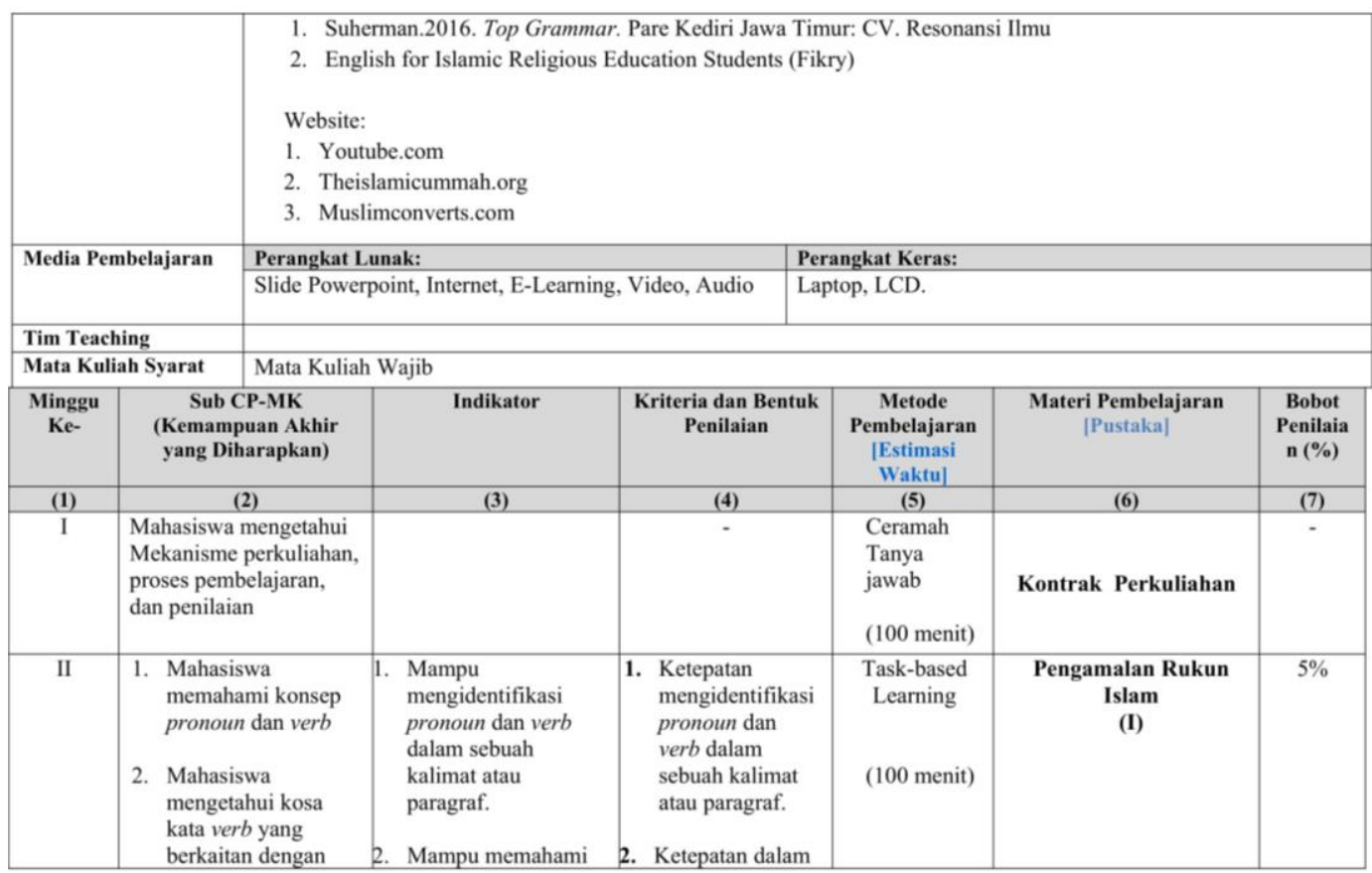




\begin{tabular}{|c|c|c|c|c|c|c|}
\hline & \begin{tabular}{|l} 
pengamalan rukun \\
Islam \\
3. \\
Mahasiswa \\
mengetahui 5 Rukun \\
Islam dalam Bahasa \\
Inggris.
\end{tabular} & $\begin{array}{l}\text { makna kosa kata } \\
\text { verb yang berkaitan } \\
\text { dengan pengamalan } \\
\text { rukun Islam }\end{array}$ & \begin{tabular}{|l} 
menerjemahkan \\
dan \\
menggunakan \\
kosa kata verb \\
yang berkaitan \\
dengan \\
pengamalan \\
rukun Islam \\
3. Ketepatan dalam \\
mengemukakan \\
5 Rukun Islam \\
menggunakan \\
Bahasa Inggris.
\end{tabular} & & & \\
\hline III & $\begin{array}{l}\text { Mahasiswa memahami } \\
\text { penggunaan to do }\end{array}$ & $\begin{array}{l}\text { Mampu menggunakan } \\
\text { to do dalam } \\
\text { menjelaskan tata cara } \\
\text { thaharah dan shalat. }\end{array}$ & $\begin{array}{l}\text { Ketepatan } \\
\text { menggunakan to do } \\
\text { dalam menjelaskan } \\
\text { tata cara thaharah } \\
\text { dan shalat. }\end{array}$ & $\begin{array}{l}\text { Task-Based } \\
\text { Learning } \\
\text { (100 menit) }\end{array}$ & $\begin{array}{l}\text { Pengamalan Rukun } \\
\text { Islam } \\
\text { (II) }\end{array}$ & $10 \%$ \\
\hline IV & $\begin{array}{l}\text { 1. Mahasiswa } \\
\text { mengetahui kosa kata } \\
\text { verb yang berkaitan } \\
\text { dengan aktivitas } \\
\text { positif sebagai } \\
\text { seorang muslim } \\
\text { 2. Mahasiswa } \\
\text { memahami konsep } \\
\text { verb-ing } \\
\text { 3. Mahasiswa } \\
\text { memahami }\end{array}$ & $\begin{array}{l}\text { 1. Mampu memahami } \\
\text { makna kosa kata } \\
\text { verb yang berkaitan } \\
\text { dengan aktivitas } \\
\text { positif sebagai } \\
\text { seorang muslim } \\
\text { 2. Mampu } \\
\text { menggunakan to be } \\
\text { (am, is , are })+ \text { verb- } \\
\text { ing dalam } \\
\text { mengemukakan } \\
\text { aktivitas positif }\end{array}$ & $\begin{array}{l}\text { 1. Ketepatan dalam } \\
\text { menerjemahkan } \\
\text { dan } \\
\text { menggunakan } \\
\text { kosa kata verb } \\
\text { yang berkaitan } \\
\text { dengan aktivitas } \\
\text { positif sebagai } \\
\text { seorang muslim } \\
\text { 2. Ketepatan } \\
\text { menggunakan to } \\
\text { be (am, is ,are) + }\end{array}$ & $\begin{array}{l}\text { Task-based } \\
\text { Learning } \\
\text { (100 menit) }\end{array}$ & Muslim & $10 \%$ \\
\hline
\end{tabular}

\begin{tabular}{|c|c|c|c|c|c|c|c|c|}
\hline & & $\begin{array}{l}\text { penggunaan to be } \\
\text { (am,is, are) + verb- } \\
\text { ing }\end{array}$ & & $\begin{array}{l}\text { sebagai seorang } \\
\text { muslim }\end{array}$ & $\begin{array}{l}\text { verb-ing dalam } \\
\text { mengemukakan } \\
\text { aktivitas positif } \\
\text { sebagai seorang } \\
\text { muslim }\end{array}$ & & & \\
\hline $\mathrm{V}$ & 1. & $\begin{array}{l}\text { Mahasiswa } \\
\text { mengetahui kosa kata } \\
\text { verb yang berkaitan } \\
\text { dengan upaya } \\
\text { membangun generasi } \\
\text { Islami. } \\
\text { Mahasiswa } \\
\text { memahami konsep } \\
\text { will + verb I }\end{array}$ & 2. & $\begin{array}{l}\text { Mampu memahami } \\
\text { makna kosa kata } \\
\text { verb yang berkaitan } \\
\text { dengan upaya } \\
\text { membangun generasi } \\
\text { Islami. } \\
\text { Mampu } \\
\text { menggunakan } \\
\text { will+verb I dalam } \\
\text { mengemukakan hal- } \\
\text { hal yang berkaitan } \\
\text { dengan upaya } \\
\text { membangun generasi } \\
\text { Islami. }\end{array}$ & $\begin{array}{l}\text { 1. Ketepatan dalam } \\
\text { menerjemahkan } \\
\text { dan } \\
\text { menggunakan } \\
\text { kosa kata verb } \\
\text { yang berkaitan } \\
\text { dengan upaya } \\
\text { membangun } \\
\text { generasi Islami. } \\
\text { 2. Ketepatan dalam } \\
\text { menggunakan } \\
\text { will+verb I dalam } \\
\text { mengemukakan } \\
\text { hal-hal yang } \\
\text { berkaitan dengan } \\
\text { upaya } \\
\text { membangun } \\
\text { generasi Islami. }\end{array}$ & $\begin{array}{l}\text { Task-based } \\
\text { Learning } \\
\text { (100 menit) }\end{array}$ & Generasi Islami & $10 \%$ \\
\hline VI & 1. & $\begin{array}{l}\text { Mahasiswa } \\
\text { memahami konsep } \\
\text { Adjective, Noun, dan } \\
\text { Adverb } \\
\text { Mahasiswa } \\
\text { mengetahui kosa kata } \\
\text { Adjective, Noun, dan }\end{array}$ & 1. & $\begin{array}{l}\text { Mampu } \\
\text { mengidentifikasi } \\
\text { Adjective, Noun, dan } \\
\text { Adverb dalam } \\
\text { sebuah kalimat atau } \\
\text { paragraf. } \\
\text { Mampu memahami }\end{array}$ & $\begin{array}{l}\text { 1. Ketepatan } \\
\text { mengidentifikasi } \\
\text { Adjective, Noun, } \\
\text { dan Adverb } \\
\text { dalam sebuah } \\
\text { kalimat atau } \\
\text { paragraf. }\end{array}$ & $\begin{array}{c}\text { Task-based } \\
\text { Learning } \\
\text { (100 menit) }\end{array}$ & $\begin{array}{l}\text { Tokoh Islam Inspiratif } \\
\text { (I) }\end{array}$ & $10 \%$ \\
\hline
\end{tabular}




\begin{tabular}{|c|c|c|c|c|c|c|}
\hline & $\begin{array}{l}\text { Adverb yang } \\
\text { berkaitan dengan } \\
\text { tokoh-tokoh Islam } \\
\text { inspiratif. }\end{array}$ & $\begin{array}{l}\text { makna kosa kata } \\
\text { Adjective, Noun, dan } \\
\text { Adverb yang } \\
\text { berkaitan dengan } \\
\text { tokoh-tokoh Islam } \\
\text { inspiratif. }\end{array}$ & $\begin{array}{l}\text { 2. Ketepatan } \\
\text { menerjemahkan } \\
\text { dan menggunakan } \\
\text { kosa kata } \\
\text { Adjective, Noun, } \\
\text { dan Adverb yang } \\
\text { berkaitan dengan } \\
\text { tokoh-tokoh Islam } \\
\text { inspiratif. }\end{array}$ & & & \\
\hline VII & $\begin{array}{l}\text { 1. Mahasiswa memahami } \\
\text { penggunaan to be } \\
\text { (am, is, are) }+ \text { ANA } \\
\text { (Adjective, Noun, } \\
\text { Adverb) } \\
\text { 2. Mahasiswa } \\
\text { memahami } \\
\text { penggunaan to be } \\
\text { (was, were) }+ \text { ANA } \\
\text { (Adjective, Noun, } \\
\text { Adverb) }\end{array}$ & $\begin{array}{l}\text { 1. Mampu } \\
\text { menggunakan to be } \\
\text { (am, is, are) }+ \text { ANA } \\
\text { (Adjective, Noun, } \\
\text { Adverb) dalam } \\
\text { mendeskripsikan } \\
\text { tokoh-tokoh Islam } \\
\text { inspiratif. } \\
\text { 2. Mampu } \\
\text { menggunakan to be } \\
\text { (was, were) }+ \text { ANA } \\
\text { (Adjective, Noun, } \\
\text { Adverb) dalam } \\
\text { menceritakan } \\
\text { biografi singkat } \\
\text { tokoh-tokoh Islam } \\
\text { inpiratif }\end{array}$ & $\begin{array}{l}\text { 1. Ketepatan } \\
\text { menggunakan to } \\
\text { be (am, is, are) }+ \\
\text { ANA (Adjective, } \\
\text { Noun, Adverb) } \\
\text { dalam } \\
\text { mendeskripsikan } \\
\text { tokoh-tokoh } \\
\text { Islam inspiratif. } \\
\\
\text { 2. Ketepatan } \\
\text { menggunakan to } \\
\text { be (was, were) + } \\
\text { ANA (Adjective, } \\
\text { Noun, Adverb) } \\
\text { dalam } \\
\text { menceritakan } \\
\text { biografi singkat } \\
\text { tokoh-tokoh } \\
\text { Islam inspiratif. }\end{array}$ & $\begin{array}{l}\text { Task-based } \\
\text { Learning } \\
\text { (100 menit) }\end{array}$ & $\begin{array}{l}\text { Tokoh Islam Inspiratif } \\
\text { (II) }\end{array}$ & $10 \%$ \\
\hline VIII & \multicolumn{5}{|c|}{ UTS } & \\
\hline
\end{tabular}

\begin{tabular}{|c|c|c|c|c|c|c|}
\hline IX & $\begin{array}{l}\text { 1. Mahasiswa } \\
\text { memahami konsep } \\
\text { verb II dan verb III } \\
\text { 2. Mahasiswa } \\
\text { mengetahui kosa kata } \\
\text { verb I, verb II, dan } \\
\text { verb III yang } \\
\text { berkaitan dengan } \\
\text { tokoh-tokoh Islam } \\
\text { inspiratif. }\end{array}$ & $\begin{array}{l}\text { 1. Mampu } \\
\text { mengidentifikasi } \\
\text { verb I, verb II, dan } \\
\text { verb III dalam } \\
\text { sebuah kalimat atau } \\
\text { paragraf. } \\
\\
\text { 2. Mampu memahami } \\
\text { makna kosa kata } \\
\text { verb I, verb II, dan } \\
\text { verb III yang } \\
\text { berkaitan dengan } \\
\text { tokoh-tokoh Islam } \\
\text { inspiratif. }\end{array}$ & \begin{tabular}{|l} 
1. Ketepatan \\
mengidentifikasi \\
verb I, verb II, \\
dan verb III \\
dalam sebuah \\
kalimat atau \\
paragraf. \\
\\
2. Ketepatan dalam \\
menerjemahkan \\
dan \\
menggunakan \\
kosa kata verb I, \\
verb II, dan verb \\
III yang \\
berkaitan dengan \\
tokoh-tokoh \\
Islam inspiratif.
\end{tabular} & $\begin{array}{l}\text { Task-based } \\
\text { Learning }\end{array}$ & $\begin{array}{l}\text { Tokoh Islam Inspiratif } \\
\text { (III) }\end{array}$ & $5 \%$ \\
\hline $\mathrm{X}$ & $\begin{array}{l}\text { 1. Mahasiswa } \\
\text { memahami } \\
\text { penggunaan did } \\
\text { 2. Mahasiswa } \\
\text { memahami } \\
\text { penggunaan to have }\end{array}$ & $\begin{array}{l}\text { 1. Mampu } \\
\text { menggunakan did } \\
\text { dalam menceritakan } \\
\text { biografi singkat } \\
\text { tokoh-tokoh Islam } \\
\text { inpiratif } \\
\text { 2. Mampu } \\
\text { menggunakan to } \\
\text { have dalam } \\
\text { menceritakan } \\
\text { biografi singkat }\end{array}$ & $\begin{array}{l}\text { 1. Ketepatan } \\
\text { menggunakan } \\
\text { did dalam } \\
\text { menceritakan } \\
\text { biografi singkat } \\
\text { tokoh-tokoh } \\
\text { Islam inpiratif } \\
\text { 2. Ketepatan } \\
\text { menggunakan to } \\
\text { have dalam } \\
\text { menceritakan }\end{array}$ & $\begin{array}{c}\text { Task-based } \\
\text { Learning }\end{array}$ & $\begin{array}{c}\text { Tokoh Islam Inspiratif } \\
\text { (IV) }\end{array}$ & $10 \%$ \\
\hline
\end{tabular}




\begin{tabular}{|c|c|c|c|c|c|c|}
\hline & & $\begin{array}{l}\text { tokoh-tokoh Islam } \\
\text { inpiratif }\end{array}$ & $\begin{array}{l}\text { biografi singkat } \\
\text { tokoh-tokoh } \\
\text { Islam inpiratif }\end{array}$ & & & \\
\hline $\mathrm{XI}$ & $\begin{array}{l}\text { 1. Mahasiswa } \\
\text { mengetahui } 6 \text { Rukun } \\
\text { Iman dalam Bahasa } \\
\text { Inggris. } \\
\text { 2. Mahasiswa } \\
\text { memahami } \\
\text { penggunaan active } \\
\text { and passive voice }\end{array}$ & $\begin{array}{l}\text { 1. Mampu } \\
\text { mengemukakan } 6 \\
\text { Rukun Iman } \\
\text { menggunakan } \\
\text { Bahasa Inggris. } \\
\text { 2. Mampu } \\
\text { menggunakan } \\
\text { active and passive } \\
\text { voice dalam } \\
\text { mengemukakan } \\
\text { hal-hal yang } \\
\text { berkaitan dengan } \\
\text { pengamalan Rukun } \\
\text { Iman. }\end{array}$ & $\begin{array}{l}\text { 1. Ketepatan dalam } \\
\text { mengemukakan } \\
6 \text { Rukun Iman } \\
\text { menggunakan } \\
\text { Bahasa Inggris. } \\
\text { 2. Ketepatan } \\
\text { menggunakan } \\
\text { active and } \\
\text { passive voice } \\
\text { dalam } \\
\text { mengemukakan } \\
\text { hal-hal yang } \\
\text { berkaitan dengan } \\
\text { pengamalan } \\
\text { Rukun Iman. }\end{array}$ & $\begin{array}{l}\text { Task-based } \\
\text { Learning }\end{array}$ & $\begin{array}{c}\text { Pengamalan Rukun } \\
\text { Iman }\end{array}$ & $5 \%$ \\
\hline XII & $\begin{array}{l}\text { 1. Mahasiswa } \\
\text { mengetahui kosa kata } \\
\text { yang berhubungan } \\
\text { dengan Rasul ulul } \\
\text { azmi } \\
\text { 2. } \begin{array}{l}\text { Mahasiswa } \\
\text { memahami } \\
\text { penggunaan } 5 \mathrm{~W}+1 \mathrm{H}\end{array}\end{array}$ & $\begin{array}{l}\text { 1. Mampu memahami } \\
\text { makna kosa kata } \\
\text { yang berhubungan } \\
\text { dengan Rasul ulul } \\
\text { azmi } \\
\text { 2. Mampu } \\
\text { menggunakan } \\
5 \mathrm{~W}+1 \mathrm{H} \text { menuliskan } \\
\text { poin-poin penting } \\
\text { dari kisah teladan }\end{array}$ & \begin{tabular}{|l|} 
1. \\
Ketepatan \\
menerjemahkan \\
dan \\
menggunakan \\
kosa kata yang \\
berhubungan \\
dengan Rasul ulul \\
azmi \\
2. Ketepatan \\
menggunakan
\end{tabular} & $\begin{array}{l}\text { Task-based } \\
\text { Learning }\end{array}$ & Rasul Ulul Azmi & $10 \%$ \\
\hline
\end{tabular}

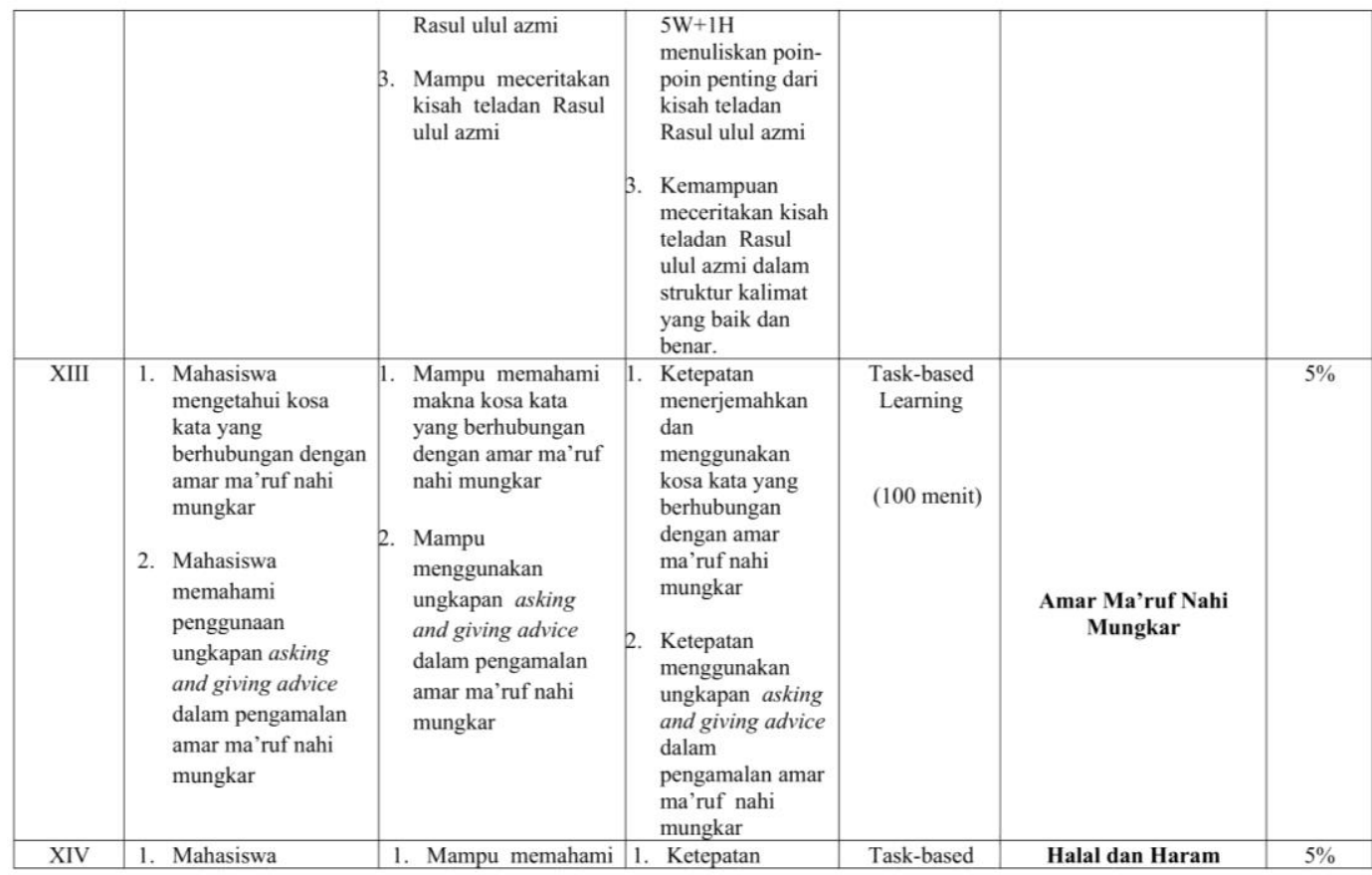




\begin{tabular}{|c|c|c|c|c|c|c|c|c|c|}
\hline & 2. & $\begin{array}{l}\text { mengetahui kosa } \\
\text { kata yang } \\
\text { berhubungan dengan } \\
\text { sesuatu yang halal } \\
\text { dan haram dalam } \\
\text { Islam. } \\
\text { Mahasiswa } \\
\text { memahami } \\
\text { penggunaan } \\
\text { ungkapan showing } \\
\text { prohibition dalam } \\
\text { mengemukakan } \\
\text { sesuatu yang halal } \\
\text { dan haram dalam } \\
\text { Islam. }\end{array}$ & & $\begin{array}{l}\text { makna kosa kata } \\
\text { yang berhubungan } \\
\text { dengan sesuatu } \\
\text { yang halal dan } \\
\text { haram dalam Islam. } \\
\text { Mampu } \\
\text { menggunakan } \\
\text { ungkapan showing } \\
\text { prohibition dalam } \\
\text { mengemukakan } \\
\text { sesuatu yang halal } \\
\text { dan haram dalam } \\
\text { Islam. }\end{array}$ & & $\begin{array}{l}\text { menerjemahkan } \\
\text { dan } \\
\text { menggunakan } \\
\text { kosa kata yang } \\
\text { berhubungan } \\
\text { dengan sesuatu } \\
\text { yang halal dan } \\
\text { haram dalam } \\
\text { Islam. } \\
\text { Ketepatan } \\
\text { menggunakan } \\
\text { ungkapan } \\
\text { showing } \\
\text { prohibition } \\
\text { dalam } \\
\text { mengemukakan } \\
\text { sesuatu yang } \\
\text { halal dan haram } \\
\text { dalam Islam. }\end{array}$ & $\begin{array}{l}\text { Learning } \\
\text { (100 menit) }\end{array}$ & & \\
\hline XV & 1. & $\begin{array}{l}\text { Mahasiswa } \\
\text { mengetahui kosa } \\
\text { kata yang } \\
\text { berhubungan dengan } \\
\text { Pendidikan Islam di } \\
\text { Indonesia. } \\
\text { Mahasiswa } \\
\text { memahami } \\
\text { penggunaan } \\
\text { ungkapan asking } \\
\text { and giving opinion }\end{array}$ & 2. & $\begin{array}{l}\text { Mahasiswa } \\
\text { memahami makna } \\
\text { kosa kata yang } \\
\text { berhubungan dengan } \\
\text { Pendidikan Islam di } \\
\text { Indonesia. } \\
\text { Mampu } \\
\text { menggunakan } \\
\text { ungkapan asking } \\
\text { and giving opinion } \\
\text { dalam berdiskusi }\end{array}$ & & $\begin{array}{l}\text { Ketepatan } \\
\text { menerjemahkan } \\
\text { dan } \\
\text { menggunakan } \\
\text { kosa kata yang } \\
\text { berhubungan } \\
\text { dengan } \\
\text { Pendidikan } \\
\text { Islam di } \\
\text { Indonesia. } \\
\text { Ketepatan }\end{array}$ & $\begin{array}{c}\text { Task-based } \\
\text { Learning }\end{array}$ & $\begin{array}{l}\text { Pendidikan Islam di } \\
\text { Indonesia }\end{array}$ & $10 \%$ \\
\hline
\end{tabular}

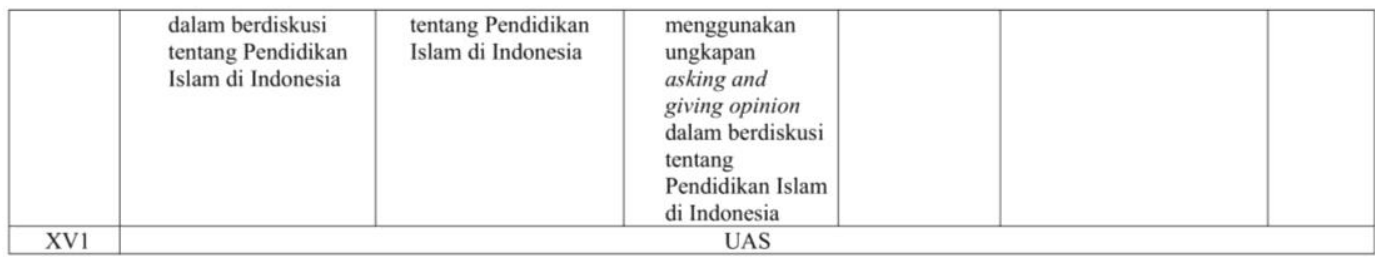

Palopo,

Dosen Penyaji,

\section{DISCUSSION}

The designed syllabus as the product of this research was designed by using 4D (Defining, Designing, Developing, and Disseminating) models research method. It also utilized ESP (English for Specific Purposes) approach in designing the syllabus. The procedures in designing an ESP syllabus are related to 4D models procedures, it is conducting students' needs before designing a syllabus. However, in designing syllabus, the researcher related needs' analysis result with the valid curriculum in Islamic Education study program i.e. INQF (Indonesian National Qualification Framework). Finally, as the result of Experts' Validation and students' perception in try-out, the designed syllabus of English for Islamic Education are appropriate with the students.

\section{CONCLUSION}

The English syllabus that is appropriate with the students includes several components:

a. Learning goal of English for Islamic Education is to communicate both oral and written using English in as Islamic students and Islamic Education teacher, 
b. Learning materials: English Material is basic English and vocabulary including part of speech, auxiliary verb (to be, to do, to have, and modals), question words, active and passive voice, asking and giving advice, showing prohibition, and asking and giving opinion. Islamic Material including the five pillars of Islam, the six pillars of faith, how to perform thaharah and Islamic prayer, inspirational Islamic figure, Ulul Azm prophet, Amar ma'ruf nahi mungkar, haram and halal, and Islamic education in Indonesia,

c. Learning Methodology is task-based learning,

d. Learning Media are picture, video, and social media.

The expert validation for the designed syllabus and students' perception about the material are excellent means can be used in learning English for Islamic Education for the first semester students.

\section{REFERENCES}

Al-Manduriy, Shohibul Muttaqien. "The Need To Use Contrastive Analysis for Elt in Islamic Higher Education Institutions." OKARA: Jurnal Bahasa Dan Sastra 12, no. 1 (2018): 87. doi:10.19105/ojbs.v12i1.1764.

Amin, Kamarudin. "Standar Kompetensi Lulusan (SKL) Dan Capaian Pembelajaran Lulusan (CPL) Program Studi Jenjang Sarjana Pada Perguruan Tinggi Keagamaan Islam Dan Fakultas Agama Islam (FAI) Pada Perguruan Tinggi," 2018. http://diktis.kemenag.go.id/NEW/file/dokumen/2815324462893280LFULL.pdf.

Arifin, Zainal. Evaluasi Pembelajaran. Bandung: PT. Remaja Rosda Karya, 2013.

Badruddin, Dahniar. "Developing a Task-Based Syllabus Based on Needs Analysis for Midwifery At Uin Alauddin Makassar." ETERNAL (English, Teaching, Learning and Research Journal) 1, no. 1 (2016): 112-30. doi:10.24252/eternal.v11.2015.a4.

Barathayomi, Wieka, Dina Rachmawati, and Rita Handayani. "Designing English for Specific Purpose Syllabus for Editing Course." The Journal of English Language Studies 01, no. 02 (2016): 2527-7022.

Basturkmen, Helen. Developing Course in English for Specific Purposes. New York: Palgrave Macmillan, 2010.

Borg, and Gall. Education Research: An Introduction. London: Longman, 1983.

Carver, D. “Some Prepositions about ESP.” The ESP Journal 2, no. 2 (1983): 131-37.

Darajat, Zakiah. Materi Pokok Pendidikan Agama Islam. Jakarta: Proyek Pembinaan Pendidikan Agama Islam Pada Perguruan Tinggi Depag dan Universitas Terbuka Depdikbud, 1993.

- - Metodik Khusus Pengajaran Agama Islam. Jakarta: Bumi Aksara, 2004.

Dick, Walter, and Lou Carey. The Systematic Design of Instruction. Addison-Wesley Educational Publisher Inc, 2001.

Douglas L., Susan, and Munir A. Shaikh. "Defining Islamic Education." Current Issues in Comparative Education 7, no. 1 (2004): 5-18. doi:10.1109/PDP.2007.55.

Dudley-Evans, T, and MJ St. John. Development in English for Specific Purposes. Cambridge: Cambridge University Press, 1998.

Gerlach, V.S., and D.P. Ely. Teaching and Media: A Systematic Approach. New Jersey: 
Prentice-Hall, Inc, 1980.

Habanakah, Abdurrahman. Pokok-Pokok Akidah Islam. Jakarta: Gema Insani, 1998.

Hall, Stephen, and David Crabbe. English for Business and Technology Course Design. Singapore: SEAMEO RELC, 1994.

Hutchinson, Tom, and Alan Waters. English for Specific Purposes. 1st ed. Cambridge: Cambridge University Press, 1987.

Ibrahim, Adzikra. "Pengertian Pendidikan Agama Islam." Accessed June 30, 2020. https://pengertiandefinisi.com/pengertian-pendidikan-agama-islam/.

Idham, Khalid. "AKAR-AKAR DAKWAH ISLAMIYAH (AKIDAH, IBADAH, DAN SYARIAH)." Orasi Jurnal Dakwah Dan Komunikasi 8, no. 1 (2017): 68-85.

Ilham, D. (2020). The Challenge of Islamic Education and How to Change. International Journal of Asian Education, 1(1), 15-20. https://doi.org/10.46966/ijae.v1i1.16

Johns, A.M. English for Specific Purposes (ESP): Its History and Contributions. Boston: Heinle \& Heinle, 1991.

Jono, Ali Akbar (Fakultas Tarbiyah dan Tadris IAIN Bengkulu). "Studi Implementasi Kurikulum Berbasis Kkni Pada Program Studi Pendidikan Bahasa Inggris Di Lptk SeKota Bengkulu." MANHAJ 4, no. 1 (2017). doi:http://dx.doi.org/10.1161/mhj.v4i1.148.

Krahnke, K.J. Approaches to Syllabus for Foreign Language Teaching. New Jersey: PrenticeHall Inc, 1987.

Long, Michael H. "Overview: A Rationale for Needs Analysis and Needs Analysis Research." Second Language Needs Analysis, 2010, 1-16. doi:10.1017/cbo9780511667299.001.

Majid, Abdul, and Dian Andayani. Pendidikan Agama Islam Berbasis Kompetensi Konsep Dan Implementasi Kurikulum 2004. Bandung: PT. Remaja Rosda Karya, 2004.

Mataram, Iain. "Developing English for Islamic Studies for Students of Islamic Education Department Mataram State Institute for Islamic Studies (IAIN Mataram) Muhsinin." Prosiding Seminar Nasional ISBN (2013): 978-602.

Matejka, Ken, and Lance B. Kurke. "Designing a Great Syllabus.” College Teaching 42, no. 3 (1994). doi:10.1080/87567555.1994.9926838.

McKey, S. "Syllabus: Structural, Situational, and Notional." TESOL Newsletter 12, no. 5 (1978).

Nunan, D. Syllabus Design. Oxford: Oxford University Press, 1988.

Nurwandani, Paristiyani, Ridwan Roy Tutupoho, and Edy Mulyono. "Panduan Penyusunan Kurikulum. Kementrian Riset, Teknologi Dan Pendidikan Tinggi Direktorat Jenderal Pembelajaran Dan Kemahasiswaan Direktorat Pembelajaran.," 2016, 79.

Print. Curriculum Development and Design. 2nd ed. Australia: Allenand Uuwin, 1993. 